UPPSALA UNIVERSITET
Working Paper 2005:10

Department of Economics

Exchange Rates and Asymmetric Shocks in Small Open Economies

Annika Alexius and Erik Post 
Department of Economics

Uppsala University

P.O. Box 513

SE-751 20 Uppsala

Sweden

Fax: +4618471 1478
Working paper 2005:10

March 2005

ISSN 0284-2904

ExCHANGE RATES AND Asymmetric SHOCKS IN

SMALl Open ECONOMIES

AnNika Alexius And ERIK Post

Papers in the Working Paper Series are published on internet in PDF formats.

Download from http://www.nek.uu.se

or from S-WoPEC http://swopec.hhs.se/uunewp / 


\title{
Exchange rates and asymmetric shocks in small open economies
}

\author{
Annika Alexius* and Erik Post $t^{+\frac{1}{9}}$
}

March 2005

\begin{abstract}
If floating exchange rates stabilize shocks rather than create shocks, a country that joins a monetary union or fixes its exchange rate looses a stabilizing mechanism. We use a first difference structural VAR on trade weighted macroeconomic data to study the role of floating exchange rates for five "small open economies" with inflation targets. By including both domestic and foreign variables and using a combination of long and short-run restrictions, we identify asymmetric shocks more carefully than previous studies. Only in Sweden and Canada does the nominal exchange rate appreciate significantly in response to asymmetric demand shocks and depreciate to asymmetric supply shocks. Most exchange rate movements are caused by speculation and are not responses to fundamental shocks. However, these exchange rate shocks have negligible effects on output and inflation. Our findings indicate that exchange rates are neither stabilizing nor destabilizing but may be loosely characterized as disconnected from the rest of the economy.
\end{abstract}

Key words: Exchange rates, asymmetric shocks, structural VAR JEL classification: F31

*Department of Economics, Uppsala University, Box 513, SE-751 20 Uppsala, Sweden. Tel: +46 18 4711564. Fax +46 18 4711478. E-mail: annika.alexius@nek.uu.se.

${ }^{\dagger}$ Department of Economics, Uppsala University, Box 513, SE-751 20 Uppsala, Sweden. Tel: +46 18 4717638. Fax +4618 4711478. E-mail: Erik.Post@nek.uu.se.

¥The second author gratefully acknowledges financial support from Handelsbankens forskningsstiftelser.

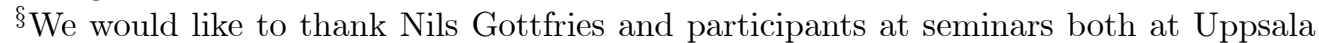
University and the Riksbank for helpful advice and useful comments. 


\section{Introduction}

Some small open economies have floating exchange rates and other small open economies either peg their exchange rate to that of a large country or participate in a monetary union. There is an ongoing debate about the pros and cons of a floating exchange rate regime. A crucial argument concerns the stabilizing role of a freely floating exchange rate. If the exchange rate moves in a stabilizing manner in response to shocks that hit the small country differently from the anchor economy, entering into a monetary union implies that the small open economy looses a stabilizing instrument. On the other hand, substantial evidence indicates that floating exchange rates are susceptible to non-fundamental shocks and therefore may create unnecessary variability (see for instance Buiter (2000)). It is an undisputable fact that nominal exchange rates are highly variable. Are these exchange rate movements responses to fundamental shocks and or can they be characterized as disconnected from the rest of the economy?

Several different approaches have been employed to investigate whether exchange rates stabilize or destabilize economies. Bergvall (2000) and Hochreiter, Korinek and Siklos (2003) conduct counterfactual experiments to study the effects of alternative exchange rate arrangements. Other authors use the results from Meese and Rogoff (1983a), Meese and Rogoff (1983b) and subsequent research about (the absence of) a relationship between exchange rates and fundamental variables as indirect evidence that exchange rates do not stabilize the economy. To find out how exchange rates respond to various shocks, it is important to be able to identify these shocks from observable data. The most common and most direct way of investigating the stabilizing role of exchange rates is to use a structural vector autoregressive model (SVAR) to extract the responses of different variables to shocks.

Previous studies using SVARs to address the stabilizing or destabilizing role of exchange rates include Clarida and Galí (1994), Canzoneri, Valles and Vinals (1996), Thomas (1997), Funke (2000), Bjorneland (2004) and Farrant and Peersman (2004). These models use different variables in the VAR to identify shocks labelled as supply shocks, demand shocks, monetary shocks and nominal shocks. Original variables are transformed into relative variables $^{1}$ so that any shock that does not have a perfectly symmetric effect on the two countries is labelled asymmetric.

Another issue concerns the variance decomposition of exchange rates. To what extent are movements in exchange rates caused by different shocks at various horizons? Canzoneri et al. (1996), Funke (2000) and Bjorneland

\footnotetext{
${ }^{1}$ e.g. $\log ($ GDP for Sweden $)-\log ($ GDP for USA $)$
} 
(2004) study the variance decompositions of output and exchange rates to establish to what extent movements in output and exchange rate are caused by the same shocks. All three studies conclude that output and exchange rate predominantly respond to different shocks. Artis and Ehrmann (2000) find that only a small portion of the movements in exchange rates are caused by real supply and demand shocks. In these studies the impulse responses of exchange rates to supply and demand shocks are insignificant in all cases. They find that as much as ninety percent of the movements in the Swedish exchange rate is due to exchange rate shocks at all horizons, but they also conclude that these shocks are not transmitted to the price level nor the real economy. Farrant and Peersman (2004) use sign restrictions instead of long-run zero restrictions to identify the different shocks. Their conclusion is similar to the other studies in that most exchange rate fluctuations are due to monetary and exchange rate shocks.

Although studies partly have examined the questions raised in this paper we believe there is still room for significant improvement. Firstly, to our knowledge this is the first study that focus narrowly on inflation target periods of small open economies. We believe that by isolating those periods we can be more certain that major structural shifts in the policy of the government with regards to stabilization policy have not occurred. Furthermore, the expected response of the exchange rate to different shocks is more obvious. Secondly, our choice of trade weighted non-relative variables seems more natural in the sense that it allows for both world-wide symmetric shocks as well as domestic asymmetric shocks. It then follows that we can keep track of the exchange rate response to both symmetric and asymmetric shocks. As noted by Artis and Ehrmann (2000) the relative approach imposes the restriction that the cross-country effects are similar whereas the non-relative approach does not. This restriction seems quite plausible is studying countries of similar economic size, but considering that most of this literature is preoccupied with stabilization properties of small open economies and that many of these studies use the USA as the anchor economy we find the relative approach unappealing. In constructing a trade weighted world economy specific for each country and employing the non-relative approach we more carefully extract the various shocks than in previous studies. Thirdly, we employ a somewhat innovative identification scheme by using a combination of long and short-run restrictions to extract the underlying structural shocks whereas standard procedure in the literature in either a full set of long-run or short-run restrictions. These restriction can all be motivated on economical grounds and renders expected responses to various shocks straightforward.

The paper is organized as follows: In the next section the data collected and transformed is presented. Then we introduce the statistical model and 
the identification procedure that recovers the structural shocks. The empirical results are then presented. We conclude the section of results with a full summary and discussion of the results obtained. Conclusion and appendix conclude.

\section{Data}

The "small open economies" in this paper are Sweden, Canada, Australia, New Zealand and the United Kingdom. For all countries seasonally adjusted quarterly real GDP $(y)$, seasonally adjusted consumer price indices $(p)$ and nominal exchange rates expressed as domestic currency needed to buy one US dollar $(e)$ have been obtained from the Source OECD database for respective inflation target periods. These periods for the five countries are reported in Table 1. As the anchor world economy we have constructed separate world counterparts for the five countries using TCW (Total Competitiveness Weights) supplied by the Swedish Riksbank. All in all the 18 countries included account for more than ninety percent of the original trade weights for the five countries under survey in this paper. ${ }^{2}$ These weights are then used to construct the country-specific "world" GDP $(y *)$, "world" price level $(p *)$ and trade weighted nominal exchange rate $(e *)$ where the most important trade counterpart will contribute with the largest weight. For example, the relevant world counterpart for Canada will then consist of more than eighty percent of USA, a small contribution from Japan and marginal contributions from other countries. For Canada this multilateral approach may not yield much different results from a bilateral with the USA but for the other countries where no single trade counterpart contribute with more than one third the bilateral approach will surely be to much of a simplification and make it less likely that we will be able to separate the world shocks from the domestic. Furthermore, the bilateral approach would be far from convincing when longrun restrictions are imposed on the VAR system since this approach would then imply for example that the UK would have no long-run effect on the US. This notion of small economy long-run zero effect on the world counterpart is much more convincing when a weighted average of 18 OECD countries is applied. Of course, choosing a bilateral or multilateral approach is dependent on the kind of question one is interested in. If the aim of the study is to investigate narrowly the policy option of joining a monetary union with a major country, or pegging the exchange rate to the currency of that major country, such as the US, then the bilateral approach is appealing. If, on the

\footnotetext{
${ }^{2}$ See Appendix, section "Construction of weighted data and sample periods" for details on data handling and weights.
} 
other hand, the focus on the paper is a general assessment of the role of the exchange rate in responding to and creating variability in the economy the natural way to proceed is by construction of a multilateral world counterpart.

Table 1: Inflation target periods

\begin{tabular}{ll}
\hline \hline Country & Inflation target period \\
\hline Sweden (SWE) & $1993 \mathrm{q} 1-2004 \mathrm{q} 2$ \\
Canada (CAN) & $1991 \mathrm{q} 2-2004 \mathrm{q} 1$ \\
Australia (AUS) & $1993 \mathrm{q} 1-2004 \mathrm{q} 2$ \\
New Zealand (NZL) & $1990 \mathrm{q} 1-2003 \mathrm{q} 4$ \\
United Kingdom (UK) & $1993 \mathrm{q} 1-2004 \mathrm{q} 2$ \\
\hline \hline
\end{tabular}

Since the inflation target period for all countries is quite short we will not consider possible cointegration between the variables. Since we have good theoretical reasons to believe that real GDP, prices and nominal exchange rates are unit roots we proceed by taking first differences of our variables to produce stationary variables for estimation. ${ }^{3}$ The tests strongly indicate that the first difference variables all are stationary. ${ }^{4}$

\section{Statistical model}

A characteristic feature of this paper is the way we identify the various shocks. In the seminal article by Blanchard and Quah (1989), the identification is completed by long-run restrictions only whereas in Sims (1980) the identification is done by short-run restrictions only. We believe that in this context a combination of the two approaches yields the most convincing identification. In an $n$-variable system a total of $n(n-1) / 2$ restrictions are needed for just-identification after imposition of an identity structural shock covariance matrix. Thus, in our five variable system:

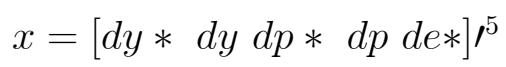

ten restrictions are needed for just-identification. Starting out with the $\operatorname{VMA}(\infty)$ form of the reduced form estimation:

$$
x_{t}=A(L) e_{t}
$$

\footnotetext{
${ }^{3}$ Remember that if our variables are individual unit roots and not cointegrated we might have a problem with spurious regression.

${ }^{4}$ For some formal unit-root tests of the first differenced variables see Appendix.

${ }^{5}$ where $\mathrm{dx}$ indicates first difference of variable $\mathrm{x}$.
} 
where $A(L)$ is the inverted lag polynomial from the reduced form estimation and $e_{t}$ the reduced form residuals. Then, assume that the structural form $\operatorname{VMA}(\infty)$ can be written as:

$$
x_{t}=C(L) \varepsilon_{t}
$$

where $C(L)$ is the structural counterpart to $A(L)$ above and $\varepsilon_{t}$ the structural shocks. Equating the two representations of the system in (1) and (2) we finally get: ${ }^{6}$

$$
C(1)=A(1) C_{0}
$$

where $C(1)$ is the long-run VMA impact matrix of the structural shocks, $A(1)$ the estimated $\operatorname{VMA}(\infty)$ from the reduced form estimation stage and $C_{0}$ the short-run matrix defining the reduced form shocks as linear combinations of the structural shocks. Maximum likelihood estimation under non-linear constraints will result in the estimation of $C_{0}$. This short run impact matrix is all we need for further analysis through impulse response functions and forecast error variance decompositions since it traces out the effects of structural shocks to the variables. From equation (3) writing out explicitly the zero restrictions:

$$
\left[\begin{array}{ccccc}
n a & \mathbf{0} & \mathbf{0} & \mathbf{0} & \mathbf{0} \\
n a & n a & \mathbf{0} & \mathbf{0} & \mathbf{0} \\
n a & \mathbf{0} & n a & \mathbf{0} & \mathbf{0} \\
n a & n a & n a & n a & n a \\
n a & n a & n a & n a & n a
\end{array}\right]=A(1)\left[\begin{array}{ccccc}
n a & n a & n a & n a & n a \\
n a & n a & n a & n a & n a \\
n a & n a & n a & n a & n a \\
n a & n a & n a & n a & \mathbf{0} \\
n a & n a & n a & n a & n a
\end{array}\right]
$$

where " $n a$ " indicates that no restriction is put on the element. The estimation of $C_{0}$ under these restrictions is performed in $\mathrm{RATS}^{7}$. Although many of the long-run responses are restricted by long-run zero restrictions this full impulse response (IR) system gives an indication of whether or not we have been able to correctly identify the different types of shocks. We would expect the directions of the IRs to be those shown in Table 2. Table 2 is essentially the left hand side of equation (4), i.e. the (long run) responses of the variables to structural shocks. The conjectured directions of the variables' responses to shocks are based on a simplified Mundell-Fleming-Dornbusch model world with a vertical supply curve as in Taylor (2004).

\footnotetext{
${ }^{6}$ See Appendix for complete derivation of (3).

${ }^{7}$ The estimation of $C_{0}$ under restrictions is done making use of the SVAR.prg code by Giannini, Lanzarotti and Seghelini found at RATS' home page: www.estima.com. The constraints are written out explicitly and in this case 10 coefficients can be written as functions of the 9 free from equation (4). Cast in the desired format the SVAR.prg program estimates $C_{0}$ with Maximum Likelihood. See appendix for derivation of constraints. This matrix is then exported to Eviews for estimation output analysis.
} 
Table 2: Expected responses to shocks

\begin{tabular}{llllll}
\hline \hline \multicolumn{3}{l}{ shock } \\
variable & $\varepsilon_{s^{*}}$ & $\varepsilon_{s}$ & $\varepsilon_{d^{*}}$ & $\varepsilon_{d}$ & $\varepsilon_{e *}$ \\
$\mathrm{y}^{*}$ & + & 0 & 0 & 0 & 0 \\
$\mathrm{y}$ & + & + & 0 & 0 & 0 \\
$\mathrm{p}^{*}$ & - & 0 & + & 0 & 0 \\
$\mathrm{p}^{*}$ & - & - & + & + & + \\
$\mathrm{e}^{*}$ & $?$ & + & $?$ & - & + \\
\hline \hline
\end{tabular}

The shocks are identified as follows and are expected to have the following effects on the variables in the VAR system:

- The shock $\varepsilon_{s^{*}}$ is the shock driving world real output in the long run; we will label this shock a world supply shock. $\varepsilon_{s^{*}}$ is expected to have a long run positive effect not only on world output, but also on output in the small economy. Furthermore, we expect it to lower prices both in the world as a whole and in the small economy. ${ }^{8}$

- The shock $\varepsilon_{s}$ is the shock that, apart from $\varepsilon_{s^{*}}$, determines domestic real output in the long run, hence an asymmetric supply shock. $\varepsilon_{s}$ is expected to lower the domestic price level and if the inflation target is rigid we would expect a depreciation of the nominal exchange rate to restore inflation target level.

- The shock $\varepsilon_{d^{*}}$ has no effect on output in the long run, but potentially affects world inflation as well as domestic price level through imported inflation; we will call $\varepsilon_{d^{*}}$ a world demand shock.

- The shock $\varepsilon_{d}$ raises home price level in the long run, but has no effect on the world price level, hence we call it an asymmetric demand shock. There are two possible interpretations of this shock: either it is a real demand shock, such as an increased propensity to consume, which would result in higher prices and an appreciating nominal exchange to restore equilibrium at a lower (appreciated) real exchange rate. The other interpretation is that it is some type of financial shock, e.g. in monetary policy, that results in higher prices and a depreciating nominal exchange rate leaving the real exchange rate unaffected in the long run. In both these cases, we would expect a temporary effect on inflation and a permanent effect on the price level.

\footnotetext{
${ }^{8}$ One could for example think of the Solow-model in which capital accumulation and very persistent productivity shocks alone determine real GDP in the long run.
} 
- The last shock, $\varepsilon_{e *}$, is identified as a shock that can potentially have long-run effects on the nominal exchange rate as well as the domestic price level in the long run. Within the quarter it is not allowed to affect price. Such a restriction must necessarily be added to be able to separate the last two shocks from each other. The most common way to separate these to shocks from each other econometrically is to impose that the last shock can only have temporary effects on the next to last. ${ }^{9}$ However, we find this quite unnatural since we then, by construction, make the last shock have long lasting effects on the real exchange rate. That the financial price, the exchange rate, reacts very quickly to new information on prices but that it takes some time for changes in the exchange rate to effect pricing behavior we find intuitive. Thus, making these identifying restrictions we interpret this shock as a speculative shock, or a risk premium on holding domestic currency. This interpretation is close to that of Farrant and Peersman (2004). We would expect that in the long run prices adjust so that the real exchange rate is left unchanged. ${ }^{10}$

The summary in Table 8 of all the IRs can be though of as the empirical analog to Table 2 .

In identifying the various shocks of interests different variables could have been chosen. Some of the studies mentioned in the introduction have included interest rates to capture demand shocks. We have chosen not to, not only because of the relatively few observations in the sample, but also because we believe that our model in the most straightforward way possible is able to capture symmetric and asymmetric demand and supply shocks without taking an explicit stand on optimal monetary policy.

\section{Empirical results}

All countries considered in this paper have an appropriate first difference VAR specification according to the diagnostics of the series. The serial correlation tests indicate that a $\operatorname{VAR}(2)$ specification is appropriate for all countries. ${ }^{11}$ Country results for the chosen model are presented in terms of im-

\footnotetext{
${ }^{9}$ This is what the "long-run identification" scheme in the Appendix does.

${ }^{10}$ We will see that in fact this long-run neutrality will not hold which is also the case in Farrant and Peersman (2004). We conjecture that this could be partly explained by having too few observations to infer long-run behaviour, partly by the very long half-life of shocks to PPP.

${ }^{11}$ See Appendix for unit root as well as specification tests.
} 
pulse response functions (IRs), displayed in the Appendix, and variance decompositions. Impulse response functions can be though of as characterizing a certain variable's response to a certain structural shock with the economy initially in steady state ${ }^{12}$. The joint stationarity of the VAR system makes the variables return to steady state in the long run, i.e. the first difference effect dies out over time. Specifically, we are most interested in the short and long run responses of the exchange rate to asymmetric shocks. The objective of the variance decomposition is to study how much of the variation in the exchange rate that can be attributed to each one of the shocks in the VAR-system.

Thus, if the exchange rate appreciates significantly to an asymmetric demand shock and the asymmetric demand shocks contributes to a large portion of the total variation in the exchange rate we are inclined to believe that there is an important stabilizing role of the exchange rate. Equivalently: if the exchange rate depreciates significantly and strongly to a domestic supply shock we would say that the exchange rate provides some element of stabilization to the economy. ${ }^{13}$ Since the expected responses of the exchange rate to various shocks under an inflation target are quite straightforward we will focus on these. The world supply and demand shocks, however, will not entail such clear expectations on the response of the nominal exchange rate since we would then have to take into account other monetary authorities responses' to such shocks. Furthermore, although labelled as "symmetric" shocks, we are more uncertain about the magnitude of the shocks in different countries rendering the expected response unclear.

\subsection{Sweden}

As for all countries we can observe that long-run zero effects all are properly restricted and that many of the impulse responses are statistically insignificant at the five percent level. The diagonal "own-shock" effects are all significant at all horizons. In the long run, only the asymmetric demand shock effect on the nominal exchange rate and the world demand shock on domestic price are statistically significantly at the five percent level. ${ }^{14}$ The appreciating effect to the asymmetric demand shock is about one percent in

\footnotetext{
${ }^{12}$ With five variables and five shocks we will have a total of 25 IRs for each country.

${ }^{13}$ Note that this entails the properties of the exchange rate as responses to unforeseen shocks. If the exchange rate as a whole has provided the economy with a mechanism of stabilization remains inconclusive and here we would have to rely on counterfactual studies.

${ }^{14}$ This result hold at a marginally higher significance level with bootstrapped confidence intervals over the entire horizon.
} 
magnitude. This result is to be interpreted in the following way: if a typical shock in asymmetric demand ${ }^{15}$ hits the economy the nominal exchange rate is expected to appreciate by about one percent from its previous equilibrium value. Other short-run effects that are statistically significant are mostly of the conjectured sign. As predicted in Table 2 the exchange rate depreciate to a domestic supply shock in line with restoring inflation target.

Where does the total variation in the exchange rate come from? We would hope that it is mostly the responses to fundamental supply and demand shocks and not the result of speculative trading, i.e. shocks in the exchange rate itself. However, as can be seen in Table 3 most of the variation in fact originates from speculative shocks, but decreases somewhat over time. This result is in line with Artis and Ehrmann (2000) who also note that Sweden's exchange market looks like a source of shocks with around ninety percent of the variance in the exchange rates explained by the exchange rate shock itself at all horizons. The contribution of the other shocks to the forecast error variance remains low at all horizons. Although the impulse responses indicate a stabilizing role for the exchange rate when an asymmetric demand shock hits the economy the contribution of such shocks to the movements in the exchange rate is small. The conclusion from these results would then be that Sweden would loose some stabilization due to exchange rate movements if it joining a monetary union ${ }^{16}$, but the effect is likely to be small.

Table 3: Variance decompositions of SWE TCW-exchange rate

\begin{tabular}{lcllll}
\hline \hline Horizon & $\varepsilon_{s^{*}}$ & $\varepsilon_{s}$ & $\varepsilon_{d^{*}}$ & $\varepsilon_{d}$ & $\varepsilon_{e *}$ \\
1 & 4.8 & 6.0 & 1.3 & 0.7 & 87.2 \\
4 & 9.0 & 9.6 & 1.6 & 7.1 & 72.7 \\
12 & 11.9 & 9.3 & 1.9 & 6.9 & 70.1 \\
20 & 11.9 & 9.3 & 1.9 & 6.9 & 70.1 \\
\hline
\end{tabular}

\subsection{Canada}

For Canada the results are quite similar to those for Sweden. Few anomalies in the impulse responses are found, which supports the identification scheme. The short-run positive effects on output from demand shocks are notable. If anything, supply shocks decrease prices which is also in line with expectations. When it comes to the nominal exchange rate, the appreciating

\footnotetext{
${ }^{15}$ One could imagine a sudden positive shock in the consumers outlook on the future making them consume more of their disposable income.

16 "A monetary union" should in this paper be thought of as the countries in the weighing system. For Sweden the results do not readily apply to the EMU although the EMU contribution in the TCW is quite large.
} 
effect to asymmetric demand shocks is similar in shape and magnitude to what we find for Sweden. However, the positive and significant, or close to significant, effect of world demand shocks is different. In the short run there are significant effects of supply shocks; the world supply shock appreciate ${ }^{17}$ and the domestic supply shock depreciates the exchange rate. ${ }^{18}$ Once again, we find support for a stabilizing role of the exchange rate under the inflation target period.

As for Sweden, the largest contributor to nominal exchange rate variation is the speculative shock, although much smaller and decreasing over time. Artis and Ehrmann (2000) argue that the exchange rate shock is less important for Canada than for Sweden. The domestic supply shock accounts for a large share of variation too and as there are indications of a depreciation in response to domestic supply shocks. One could argue that the nominal exchange rate responds as to stabilize price and inflation. Thus, in the case of Canada it seems that the exchange rate provides some stabilization of the economy.

Table 4: Variance decompositions of CAN TCW-exchange rate

\begin{tabular}{lccccc}
\hline \hline Horizon & $\varepsilon_{s^{*}}$ & $\varepsilon_{s}$ & $\varepsilon_{d^{*}}$ & $\varepsilon_{d}$ & $\varepsilon_{e_{*}}$ \\
1 & 9.6 & 33.8 & 10.5 & 1.2 & 45.0 \\
4 & 11.7 & 27.7 & 13.8 & 7.7 & 39.0 \\
12 & 12.0 & 27.5 & 14.1 & 7.8 & 38.6 \\
20 & 12.0 & 27.5 & 14.1 & 7.8 & 38.6 \\
\hline
\end{tabular}

\subsection{Australia}

Australia shows one striking peculiarity in the impulse response functions, namely the positive world price-effect of a world supply shock. This result is counterintuitive in that we believe that a supply shock such as a sudden increase in productivity should lower prices. Although the effect is statistically significant, it is very small at one tenth of a percent. On the other hand, the asymmetric supply shock lowers the domestic price significantly, by roughly one percent. The nominal exchange rate seems to have some tendency to appreciate to the world supply shock, otherwise the effects are small and statistically insignificant.

\footnotetext{
${ }^{17}$ Since "the world" in this case is ninety percent USA one could imagine the following scenario: A supply shock predominantly hits the USA and the decrease in inflation makes the FED lower the interest rate which in turn depreciate the USD against the Canadian dollar.

${ }^{18}$ Short-run IRs for the exchnage rate remain unchanged with bootstrapped confidence intervals.
} 
Although the speculative shock accounts for more than half of the variation in the exchange rate at all horizons, the world supply shock seems quite important for exchange rate variation in Australia We argue that pegging the exchange rate to a basket of currencies would not be detrimental to the Australian economy since the exchange rate mainly responds to symmetric world shocks. Possibly the speculative fluctuations in the exchange rate also could be decreased with such an arrangement.

Table 5: Variance decompositions of AUS TCW-exchange rate

\begin{tabular}{lccccc}
\hline \hline Horizon & $\varepsilon_{s^{*}}$ & $\varepsilon_{s}$ & $\varepsilon_{d^{*}}$ & $\varepsilon_{d}$ & $\varepsilon_{e *}$ \\
1 & 33.1 & 0.0 & 2.2 & 1.0 & 63.7 \\
4 & 30.3 & 5.8 & 11.4 & 1.1 & 51.5 \\
12 & 30.2 & 6.2 & 11.3 & 1.3 & 51.1 \\
40 & 30.2 & 6.1 & 11.3 & 1.3 & 51.1 \\
\hline
\end{tabular}

\subsection{New Zealand}

Short-run and close to significant negative price effects of supply shocks are found for New Zealand. The most notable result is the statistically significant effect of the asymmetric supply shock on the nominal exchange rate. To the extent that the inflation target is to be enforced we find this finding striking. Imagine that there is a sudden productivity increase in the New Zealand economy only that lowers prices. If the inflation target is the main priority we would hope for the exchange rate to depreciate so as to stimulate exports and push aggregate demand. If anything, the converse happens in New Zealand. ${ }^{19}$

With reference to the above reasoning about stabilization of inflation and the appreciating movement of the exchange rate to asymmetric supply shocks we can see that although the exchange rate movements are not stabilizing per se, only a small part of exchange rate movements create (destabilizing) variability in the exchange rate. As for the other countries most of the variation come from speculative shocks in the exchange rate. It seems that, given an inflation target and the destabilizing movements in the exchange rate following asymmetric supply shocks, some increased stability could be the result of joining a monetary union. A monetary union with Australia is in fact what is proposed in Hochreiter et al. (2003).

\footnotetext{
${ }^{19}$ This results remains significant with bootstrapped confidence intervals in the short run.
} 
Table 6: Variance decompositions of NZL TCW-exchange rate

\begin{tabular}{lccccc}
\hline \hline Horizon & $\varepsilon_{s^{*}}$ & $\varepsilon_{s}$ & $\varepsilon_{d^{*}}$ & $\varepsilon_{d}$ & $\varepsilon_{e *}$ \\
1 & 0.3 & 9.3 & 3.5 & 0.5 & 86.5 \\
4 & 2.7 & 13.8 & 13.8 & 4.3 & 65.4 \\
12 & 3.9 & 13.4 & 14.4 & 4.8 & 63.5 \\
40 & 3.9 & 13.4 & 14.4 & 4.8 & 63.5 \\
\hline
\end{tabular}

\subsection{United Kingdom}

In UK, the world supply shocks tend to appreciate the pound, at least in the short to medium run. ${ }^{20}$

The major part of the nominal exchange rate variation originates from the speculative shocks, but world supply shocks account for some 25 percent in the long run. This in noteworthy considering the impulse response above indicating an appreciating movement of the currency when the economy is hit by such a shock. From the point of view of macroeconomic stability no clear-cut policy recommendation can be derived from these results.

Table 7: Variance decompositions of UK TCW-exchange rate

\begin{tabular}{lccccc}
\hline \hline Horizon & $\varepsilon_{s^{*}}$ & $\varepsilon_{s}$ & $\varepsilon_{d^{*}}$ & $\varepsilon_{d}$ & $\varepsilon_{e *}$ \\
1 & 11.7 & 0.1 & 1.9 & 0.1 & 86.2 \\
4 & 24.6 & 8.0 & 4.2 & 9.2 & 54.0 \\
12 & 24.7 & 8.2 & 4.6 & 9.2 & 53.4 \\
40 & 24.7 & 8.2 & 4.6 & 9.2 & 53.4 \\
\hline
\end{tabular}

\subsection{Empirical findings, a summary}

First we will summarize our findings of separate countries in two tables. In Table 8 all impulse responses, short-run (2 quarters) and long-run (20 quarters), for all five countries are displayed. This table asks some important question: Is our identification procedure successful? Do we come across any common findings for these five economies? Is there a pattern in how the variables respond to various types of shocks and if various results come out? Can they be explained by individual characteristics of respective countries? The second table, Table 9 will summarize the variance decompositions.

- $\varepsilon_{s^{*}}$, what we have identified as the world supply shock, tends to raise output both abroad and in the small open economy. The effect on domestic output is more pronounced in the short run. With the exception

\footnotetext{
${ }^{20}$ This results remains significant with bootstrapped confidence intervals in the short run.
} 
Table 8: Summary of country variables responses to shocks 2 and 20 quarters, ordered SWE/CAN/AUS/NZL/UK

\begin{tabular}{ccccccc}
\hline \hline & & \multicolumn{5}{c}{ variable } \\
shock & horizon & $\varepsilon_{s^{*}}$ & $\varepsilon_{s}$ & $\varepsilon_{d^{*}}$ & $\varepsilon_{d}$ & $\varepsilon_{e *}$ \\
\hline $\mathrm{y}^{*}$ & $2 \mathrm{q}$ & $+/+/+/+$ & $0 /+/+/ 0 / 0$ & $0 /+/ 0 /+/+$ & $0 / 0 / 0 / 0 / 0$ & $0 / 0 /+/ 0 / 0$ \\
& $20 \mathrm{q}$ & $+/+/+/+/+$ & $0 / 0 / 0 / 0 / 0$ & $0 / 0 / 0 / 0 / 0$ & $0 / 0 / 0 / 0 / 0$ & $0 / 0 / 0 / 0 / 0$ \\
$\mathrm{y}$ & $2 \mathrm{q}$ & $+/+/+/ 0 /+$ & $+/+/+/+/+$ & $0 /+/ 0 / 0 / 0$ & $0 / 0 /+/ 0 / 0$ & $0 / 0 / 0 / 0 / 0$ \\
& $20 \mathrm{q}$ & $0 / 0 / 0 / 0 /+$ & $+/+/+/+/+$ & $0 / 0 / 0 / 0 / 0$ & $0 / 0 / 0 / 0 / 0$ & $0 / 0 / 0 / 0 / 0$ \\
$\mathrm{p}^{*}$ & $2 \mathrm{q}$ & $0 /-/ 0 / 0 /-$ & $0 / 0 / 0 / 0 / 0$ & $+/+/+/+/+$ & $0 / 0 / 0 / 0 / 0$ & $0 / 0 / 0 / 0 / 0$ \\
& $20 \mathrm{q}$ & $0 / 0 /+/ 0 / 0$ & $0 / 0 / 0 / 0 / 0$ & $+/+/+/+/+$ & $0 / 0 / 0 / 0$ & $0 / 0 / 0 / 0$ \\
$\mathrm{p}$ & $2 \mathrm{q}$ & $-/-/ 0 /-/ 0$ & $0 /-/-/ 0 / 0$ & $+/ 0 / 0 /+/ 0$ & $+/+/+/+/+$ & $0 / 0 / 0 / 0 / 0$ \\
& $20 \mathrm{q}$ & $0 / 0 / 0 / 0 / 0$ & $0 / 0 /-/ 0 / 0$ & $+/ 0 / 0 / 0 / 0$ & $+/+/+/+/+$ & $0 / 0 / 0 / 0$ \\
$\mathrm{e}^{*}$ & $2 \mathrm{q}$ & $-/-/-/ 0 /-$ & $+/+/ 0 /-/ 0$ & $0 /+/ 0 / 0 / 0$ & $0 /-/ 0 / 0 / 0$ & $+/+/+/+/+$ \\
& $20 \mathrm{q}$ & $0 / 0 / 0 / 0 / 0$ & $0 / 0 / 0 /-/ 0$ & $0 /+/ 0 / 0 / 0$ & $-/-/ 0 / 0 / 0$ & $+/+/+/+/+$ \\
\hline \hline
\end{tabular}

of one country (Australia) this shock tends to lower prices, at least in the short run. This makes us believe that this shock can in fact be labelled a supply shock. In four out of five countries (the exception being New Zealand) the nominal exchange rate appreciates in the short run following a world supply shock. ${ }^{21}$

- $\varepsilon_{s}$, the asymmetric supply shock, lowers domestic prices in the short run in two out of five cases (Canada and Australia). The effect is negative and significant in the long run only for Australia. Although the evidence is somewhat weak the results provide some support for our identification of this shock. The exchange rate depreciates in two out of five cases (Sweden and Canada) and appreciate in one case (New Zealand).

- $\varepsilon_{d *}$ tends to raise output temporarily in three out of five countries and further increases prices in the small economy making us believe that we have correctly identified this shock as a world demand shock. The exchange rate depreciate in one case (Canada).

- $\varepsilon_{d}$ has been the hardest to identify by looking at the impulse responses. Remember that its effect on all the variables in the system except domestic price and nominal exchange rate are restricted to zero in the

\footnotetext{
${ }^{21}$ Given that the world experience a stronger effect of this shock and that the macroeconomic policy can described loosely as inflation targeting we would expect this appreciation of the small economy currency.
} 
long run. Indications of a positive short-run effect on domestic output can be found in all cases but one (Canada), but at poor significance levels. Referring to our discussion of the identification of shocks above, the shock appears to be more of a real demand shock than a financial shock in four out of five cases (the exception being the United Kingdom) since this shock tends to raise domestic prices and appreciate the nominal exchange rate, further appreciating the real exchange rate to restore equilibrium. The appreciation is statistically significant in two cases (Canada and Sweden).

- $\varepsilon_{e *}$, the speculative shock, identified as possibly affecting only domestic prices and the exchange rate in the long run, does not have any clear effect on any variable except the exchange rate itself. That the effect on the nominal exchange rate is permanent and significant would then imply that also the real exchange rate is affected. However, it is important to remember is that the way we have set up the VAR, this last shock will be identified as the long-run residual determinant of the nominal exchange rate after the other shocks have been accounted for. Keeping in mind that nominal exchange rates are characterized by fluctuations and possibly trends over time for no apparent reason, this should perhaps come as no surprise given that relative PPP does not hold even with much longer time series.

The impulse responses for the five countries differ quite remarkably and some anomalies in the expected responses have been found. Noteworthy is that for the two countries, Sweden and Canada, where it seems that our identification has been the most successful the responses of the nominal exchange rate is as expected. For the other countries, some doubts arise if we have really been able to correctly identify the various shocks and if this is indeed the case it is not surprising that the responses of the exchange rate is not in line with priors. With short samples and employing long-run identifying assumptions we could very well have such a problem.

\begin{tabular}{lccccc}
\multicolumn{6}{c}{ Table 9: Variance decompositions, summary } \\
\hline \hline Horizon & $\varepsilon_{s^{*}}$ & $\varepsilon_{s}$ & $\varepsilon_{d^{*}}$ & $\varepsilon_{d}$ & $\varepsilon_{e *}$ \\
1 & $0-33$ & $0-34$ & $1-11$ & $0-1$ & $45-87$ \\
4 & $3-30$ & $6-28$ & $2-14$ & $1-9$ & $39-73$ \\
12 & $4-30$ & $6-28$ & $2-14$ & $1-9$ & $39-70$ \\
40 & $4-30$ & $6-28$ & $2-14$ & $1-9$ & $39-70$ \\
\hline
\end{tabular}

Table 9 summarizes the variance decompositions already presented country by country above. The results indicate that supply shocks are more 
important than demand shocks for nominal exchange rate behavior but the overwhelmingly most important determinant is the speculative shock. The variance decompositions of inflation and output growth indicate that the contribution of $\varepsilon_{e *}$ is small. This further reinforces the common belief that exchange rates are neither a stabilizer nor a destabilizer but can be characterized as detached from the rest of the economy. Only for Sweden GDP does this contribution exceed ten percent and for inflation the contribution is at a mere five percent.

\section{Conclusion}

Are exchange rates stabilizing or destabilizing? Conditional on our structural VAR model, we have provided answers to several specific questions concerning the role of exchange rates and their relationship to asymmetric shocks. These results are robust to alternative specifications ${ }^{22}$.

We have studied the impulse responses of nominal exchange rates to sudden asymmetric shocks in domestic demand and supply in five small open economies. In order to stabilize output and inflation, the nominal exchange rate should appreciate when demand unexpectedly increases. Only in the case of Sweden and Canada is the appreciating response statistically significant and at around one percent in magnitude. Further, for Sweden and Canada, the exchange rate tend to depreciate to a domestic supply shock at least in the short run. We have argued that this finding is in line with an inflation target. These two findings leads us to believe that Sweden and Canada would loose some economic stability by joining a monetary union.

The forecast error variance decompositions of nominal exchange rates shows that exchange rates create shocks rather than respond to them. While floating exchange rates create variability, the shocks emanating from the exchange rate have only minor effects on the economy. Neither output nor inflation respond much to the speculative exchange rate shock.

Most of our evidence on the behavior of exchange rates is consistent with the exchange rate disconnect puzzle discussed by Obstfeld and Rogoff (2000). Exchange rates are highly variable but their movements appear to be weakly related to the rest of the economy. They are not responses to fundamental shocks and they have only minor effects on output and inflation.

\footnotetext{
${ }^{22}$ See Appendix.
} 


\section{A Appendix}

\section{A.1 Construction of weighted data and sample periods}

The same 19 OECD countries are used for all five countries in constructing the world anchor; countries and recomputed weights are displayed in the table below. We have used OECD-data from the Source OECD database for all but Luxemburg, Ireland and Portugal in the original weight system. Ireland and Portugal have been left out because of data unavailability. Also, since separate data is lacking for Luxemburg and Luxemburg is very small to Belgium we have accepted using the weight for Belgium-Luxemburg on Belgium data only. The German GDP-series is rebased from 1990q1 to 1990q4 and for Sweden constant price data is seasonally adjusted by the moving average method and thereafter used. All in all, "the world" account for 95-99 percent of total TCW. The original weights for the full set of OECD countries are re-weighted so that they sum to unity.

\begin{tabular}{|c|c|c|c|c|c|}
\hline & Country & & & & \\
\hline Weights & AUS & CAN & NZL & SWE & UK \\
\hline AUS & & $0,2 \%$ & $17,9 \%$ & $0,3 \%$ & $0,5 \%$ \\
\hline Austria & $0,5 \%$ & $0,2 \%$ & $0,4 \%$ & $1,7 \%$ & $1,2 \%$ \\
\hline Belgium-Lux. & $1,2 \%$ & $0,5 \%$ & $0,9 \%$ & $3,6 \%$ & $5,6 \%$ \\
\hline CAN & $1,8 \%$ & & $1,9 \%$ & $1,2 \%$ & $1,4 \%$ \\
\hline Denmark & $0,3 \%$ & $0,1 \%$ & $0,4 \%$ & $5,7 \%$ & $1,4 \%$ \\
\hline Finland & $0,6 \%$ & $0,2 \%$ & $0,5 \%$ & $6,8 \%$ & $1,5 \%$ \\
\hline France & $3,1 \%$ & $1,6 \%$ & $2,2 \%$ & $7,3 \%$ & $13,1 \%$ \\
\hline Germany & $8,0 \%$ & $2,8 \%$ & $6,2 \%$ & $22,7 \%$ & $23,4 \%$ \\
\hline Greece & $0,1 \%$ & $0,0 \%$ & $0,0 \%$ & $0,3 \%$ & $0,3 \%$ \\
\hline Italy & $3,2 \%$ & $1,2 \%$ & $3,3 \%$ & $6,2 \%$ & $8,6 \%$ \\
\hline Japan & $31,6 \%$ & $6,0 \%$ & $29,6 \%$ & $5,3 \%$ & $7,3 \%$ \\
\hline Netherlands & $1,3 \%$ & $0,7 \%$ & $1,3 \%$ & $4,3 \%$ & $5,9 \%$ \\
\hline NZL & $8,2 \%$ & $0,1 \%$ & & $0,1 \%$ & $0,2 \%$ \\
\hline Norway & $0,3 \%$ & $0,1 \%$ & $0,4 \%$ & $5,7 \%$ & $1,2 \%$ \\
\hline Spain & $0,5 \%$ & $0,3 \%$ & $0,4 \%$ & $2,5 \%$ & $4,0 \%$ \\
\hline SWE & $1,7 \%$ & $0,6 \%$ & $1,9 \%$ & & $3,6 \%$ \\
\hline Switzerland & $1,4 \%$ & $0,4 \%$ & $1,4 \%$ & $2,8 \%$ & $3,4 \%$ \\
\hline UK & $10,2 \%$ & $2,5 \%$ & $9,6 \%$ & $11,8 \%$ & \\
\hline USA & $26,1 \%$ & $82,6 \%$ & $21,7 \%$ & $11,8 \%$ & $17,2 \%$ \\
\hline
\end{tabular}

Transformed weights. Source: The Riksbank

All individual country series are transformed into natural logs and thereafter world weighted aggregates are computed. The exchange rates are all in domestic currency needed to buy one US dollar and the remaining bilateral exchange rates are computed manually assuming the possibility of triangular arbitrage if misaligned. 
The periods for estimation have been chosen to be those inflation target (IT) periods where the target has been announced and inflation is down within the target band. The reason for putting this requirement on data is that we are concerned with exchange rate movements when the target is in operation and not during transitional periods. New-Zealand only is affected in the sense that IT announcement was made in March 1990, but inflation was down at target level around the second quarter of 1992.

\section{A.2 Unit root tests}

In Table 10 we will report the augmented Dickey-Fuller tests (ADF-tests) for the null hypothesis of unit roots in the first differenced data of prices, GDP levels and nominal exchange rates. For each country there will be five such tests since the world weighted data differs between countries. All first difference series of the data can clearly be rejected as unit roots.

Table 10: Unit root tests

\begin{tabular}{lccccc}
\hline \hline \multicolumn{5}{c}{ country } \\
\hline variable & SWE & CAN & AUS & NZL & UK \\
dy* & $4.34(2.93)$ & $5.20(2.92)$ & $3.68(2.93)$ & $4.48(2.92)$ & $4.35(2.93)$ \\
dy & $10.03(2.93)$ & $5.17(2.92)$ & $6.58(2.93)$ & $7.44(2.92)$ & $5.64(2.93)$ \\
dp* & $6.19(2.93)$ & $5.34(2.92)$ & $5.38(2.93)$ & $6.55(2.92)$ & $6.17(2.93)$ \\
dp & $8.26(2.93)$ & $7.94(2.92)$ & $5.28(2.93)$ & $4.59(2.92)$ & $6.09(2.93)$ \\
de* & $7.50(2.93)$ & $5.30(2.92)$ & $5.20(2.93)$ & $5.39(2.92)$ & $4.45(2.93)$ \\
\hline \hline
\end{tabular}

Only constant, no time trend, admitted in test equation

SIC choose lag-length in tests, max. eight lags.

|t-values| with $5 \%$ critical values in parentheses

\section{A.3 Specification tests}

In choosing the preferred lag order model for each country we have relied on the tests for serial correlation in the residuals. In Tables 11-15 in the Appendix we report the p-values of the Portmanteau multivariate residual serial correlation test at lag length 20 and the Lagrange multiplier (LM) test at lag-length $1, \operatorname{LM}(1)$ and lag length $4, \operatorname{LM}(4)$. That the residuals are in fact non-serially correlated will be the main criteria in choosing our preferred model since we know that the estimates could be severely biased if serial correlation remain. The chosen model statistics are in italics. 
Table 11: Asymptotic p-values of residual serial correlation for Sweden

\begin{tabular}{llll}
\hline \hline Model & Portmanteau & LM(1) & LM(4) \\
\hline VAR(1) & 0.36 & 0.51 & 0.17 \\
$V A R(2)$ & 0.10 & 0.29 & 0.19 \\
$\operatorname{VAR}(3)$ & 0.02 & 0.59 & 0.13 \\
VAR(4) & 0.00 & 0.98 & 0.25 \\
\hline \hline
\end{tabular}

Table 12: Asymptotic p-values of residual serial correlation for Canada

\begin{tabular}{llll}
\hline \hline Model & Portmanteau & LM(1) & LM(4) \\
\hline $\operatorname{VAR}(1)$ & 0.48 & 0.38 & 0.64 \\
$\operatorname{VAR}(2)$ & 0.19 & 0.63 & 0.74 \\
$\operatorname{VAR}(3)$ & 0.09 & 0.86 & 0.61 \\
$\operatorname{VAR}(4)$ & 0.01 & 0.39 & 0.67 \\
\hline \hline
\end{tabular}

Table 13: Asymptotic p-values of residual serial correlation for Australia

\begin{tabular}{llll}
\hline \hline Model & Portmanteau & LM(1) & LM(4) \\
\hline $\operatorname{VAR}(1)$ & 0.53 & 0.46 & 0.47 \\
$\operatorname{VAR}(2)$ & 0.29 & 0.99 & 0.53 \\
$\operatorname{VAR}(3)$ & 0.01 & 0.80 & 0.09 \\
$\operatorname{VAR}(4)$ & 0.01 & 0.45 & 0.55 \\
\hline \hline
\end{tabular}


Table 14: Asymptotic p-values of residual serial correlation for New Zealand

\begin{tabular}{llll}
\hline \hline Model & Portmanteau & LM(1) & LM(4) \\
\hline VAR(1) & 0.28 & 0.20 & 0.25 \\
$\operatorname{VAR}(2)$ & 0.13 & 0.91 & 0.19 \\
$\operatorname{VAR}(3)$ & 0.02 & 0.21 & 0.46 \\
$\operatorname{VAR}(4)$ & 0.00 & 0.27 & 0.12 \\
\hline \hline
\end{tabular}

Table 15: Asymptotic p-values of residual serial correlation for United Kingdom

\begin{tabular}{llll}
\hline \hline Model & Portmanteau & LM(1) & LM(4) \\
\hline VAR(1) & 0.07 & 0.90 & 0.43 \\
$\operatorname{VAR}(2)$ & 0.10 & 0.55 & 0.71 \\
$\operatorname{VAR}(3)$ & 0.05 & 0.65 & 0.21 \\
$\operatorname{VAR}(4)$ & 0.02 & 0.28 & 0.15 \\
\hline \hline
\end{tabular}

Based on the specification test in Tables 11-15 a two lag VAR model was chosen for all countries. Although more lags would probably introduce some more dynamics to the system the multivariate Portmanteau serial correlation tests and parsimony make us choose the two lag specification as the preferred model. In fact lag-length criteria tests such as the likelihood ratio (LR) test generally do not suggest more than one lag dynamics. However, the JarqueBera residual normality tests generally do not reject the null of univariate and multivariate normal residuals in the two lag specification but the one lag specification show some signs of non-normality making us prefer the $\operatorname{VAR}(2)$ model.

\section{A.4 Identification}

Suppose the reduced form VAR can be written as:

$$
\begin{gathered}
D(L) x_{t}=e_{t} \\
e_{t} \sim \text { i.i.d. } N(0, \Omega)
\end{gathered}
$$

where $D(L)=D_{0}+D_{1} L+D_{2} L^{2}+\ldots+D_{p} L^{p}, L$ is the lag operator with $L_{i} x_{t}=x_{t-i}$ and $D_{0}$ the identity matrix $I$. The covariance matrix $E\left(e_{t} e_{t}^{\prime}\right)=\Omega$ of the reduced form residuals $e_{t}$ is in general non-diagonal and therefore these cannot be interpreted as structural shocks. If the roots of the characteristic polynomial in equation (5) lie outside the unit circle the matrix lag polynomial $D(L)$ is invertible and there exists an infinite order vector moving average representation: 


$$
x_{t}=A(L) e_{t}
$$

where $A(L)=D(L)^{-1}$. Note here that the matrix polynomials above, $D(L)$ and therefore also $A(L)$ can be estimated by equation by equation OLS which is consistent and under assumption of normality of the error terms efficient.

Suppose now that the VAR representation of the structural model can be written as:

$$
\begin{aligned}
& B(L) x_{t}=\varepsilon_{t} \\
& E\left(\varepsilon_{t} \varepsilon_{t}^{\prime}\right)=I
\end{aligned}
$$

so that the orthogonal shocks are all normalized to unity. If $D(L)$ is invertible so is $B(L)$ and we can proceed as above so that:

$$
x_{t}=C(L) \varepsilon_{t}
$$

where $C(L)=B(L)^{-1}$. Equation (10) has a clear economical interpretation since all the endogenous variables $x_{t}$ are expressed as distributed lags of the underlying structural shocks $\varepsilon_{t}$.

Equating equation (7) and equation (10) we have:

$$
C(L) \varepsilon_{t}=A(L) e_{t}
$$

and since $A_{0}=I$ and equation (11) must hold at each point in time we have:

$$
C_{0} \varepsilon_{t}=e_{t}
$$

saying that the estimated reduced form residuals from (5) are linear combinations of the underlying structural shocks. $C_{0}$ as such can be interpreted as the contemporaneous reaction of the variables to structural innovations. Squaring both sides of (12) and taking expectations we have:

$$
C_{0} C_{0}^{\prime}=\Omega
$$

by (6) and (9). Then combining (11) and (12) yields:

$$
C(L) \varepsilon_{t}=A(L) C_{0} \varepsilon_{t}
$$


which in turn implies that:

$$
C_{i}=A_{i} C_{0} \forall i
$$

Now, assume that $C_{0}$ is known. This means that the structural shocks $\varepsilon_{t}$ can be identified through (12) and since we have estimated $A_{i}$ in the reduced form system we can easily calculate all the structural coefficients $C_{i}$ using (15). Feeding the structural shocks to (10) the full dynamics of the system can then be described in terms of impulse response functions and variance decompositions. ${ }^{23}$

From (15) we have that:

$$
C(1)=A(1) C_{0}
$$

where $A(1)$ and $C(1)$ represent cumulated effects of innovation. $A(1)$ is deduced from reduced form estimation of (7) and restrictions on $C(1)$ can effectively be used to identify $C_{0}$. In fact, equation (16) forms the basis for the identification procedure.

If we then proceed by first difference SVAR estimation in our five variable system in order to identify the structural shocks we need to impose 25 restrictions on the $C_{0}$ matrix. By imposing an identity covariance matrix for the orthogonal structural shocks in (9) we are left with ten restrictions. There are of course many ways that these restrictions could be added using long-run or short-run restrictions or a combination of both. In this paper the main mode of attack on $C_{0}$ the usage of a combination of restriction on $C(1)$ and one directly imposed on $C_{0}$. Alternative specifications using other identification schemes are reported as robustness checks.

Just to make the reader get an idea of how the restrictions are implemented we will give a brief description of the steps:

- From (16) we have the $\operatorname{VMA}(\infty)$ matrix $A(1)$ that we know from estimation. $C(1)$ is the long-run structural shocks impact matrix where we restrict the elements as described in (4) and $C_{0}$ is the matrix defining the reduced form residuals as linear combinations of the structural shocks. All matrices are in dimensions five by five.

- Ten restrictions are needed for a just identification. We in fact impose eleven restrictions, one more than necessary but more economically plausible, which is allowed for by the estimation algorithm. Ten of

\footnotetext{
${ }^{23}$ For a theoretical overview of the VAR, representations and identification issues see Hamilton (1994).
} 
these restriction are in the $C(1)$ matrix and one in the $C_{0}$ matrix to be estimated.

- Writing out the zero-solution equations from (16) explicitly we start out with ten equations (restrictions) in 19 unknowns involving the estimates of $A(1)$. In this system we thus have ten restricted parameters and nine free. By extensive repeated substitution we end up with a system of linear constraints where the 25 parameters of $C_{0}$ (with 24 non-zero) all can be written as linear combinations of the estimated parameters in $A(1)$ and the 14 free parameters. The validity of the restrictions imposed is checked by using the identity in (16).

- The restrictions are then provided to the SVAR.prg procedure that estimates $C_{0}$ by maximum likelihood.

\section{A.5 Alternative specifications}

\section{A.5.1 Short-run identification scheme}

Using the standard short-run identification scheme is not as theoretically convincing since the shocks are directly associated by the variables in the system and identified through the sequence of admissible contemporaneous effects. See Sims (1980) original formulation. In the impulse responses we find some irregularities that we have a difficult time believing in, violating the long-run neutrality assumption inferred above and letting the small economy affect the world at all horizons. Nevertheless, it turns out that the results concerning the qualitative responses of the exchange rate remains the same, but the results tend to more accentuated and more often statistically significant in our preferred model. The variance decompositions show the same pattern of most variation at all horizons due to the last $\operatorname{shock}^{24}$, but this contribution decreases over time. A more pronounced role of the third and fourth shock is now given relative to the first and second, but since this identification scheme is non-structural in a sense it is difficult to compare the two in terms of demand and supply shocks like previously.

\section{A.5.2 Long-run identification scheme}

Using the standard recursive long-run identification scheme originally proposed by Blanchard and Quah (1989) we get the same qualitative results as

\footnotetext{
${ }^{24}$ The shock now defined as the one not having any contemporaneous effect on any of the other variables, only on the exchnage rate itself.
} 
in our preferred model. The imposition of a long-run zero response of the domestic price level to the fifth shock makes the real exchange rate appreciate by definition, which we have a difficult time to comprehend. Therefore we prefer the mixed long and short-run identification scheme. The variance decompositions remain virtually unchanged.

\section{A.6 Impulse response figures}

The full impulse response output is presented below. The accumulated effect of a one standard deviation structural shock are traced out country by country. The dotted lines are 95 percent confidence intervals based on the asymptotic standard errors. The most interesting figures, the response of the exchange rate to asymmetric demand and supply shocks are shaded in grey. 


\section{SWEDEN: Accumulated Response to One Standard Deviation Structural Innovations}
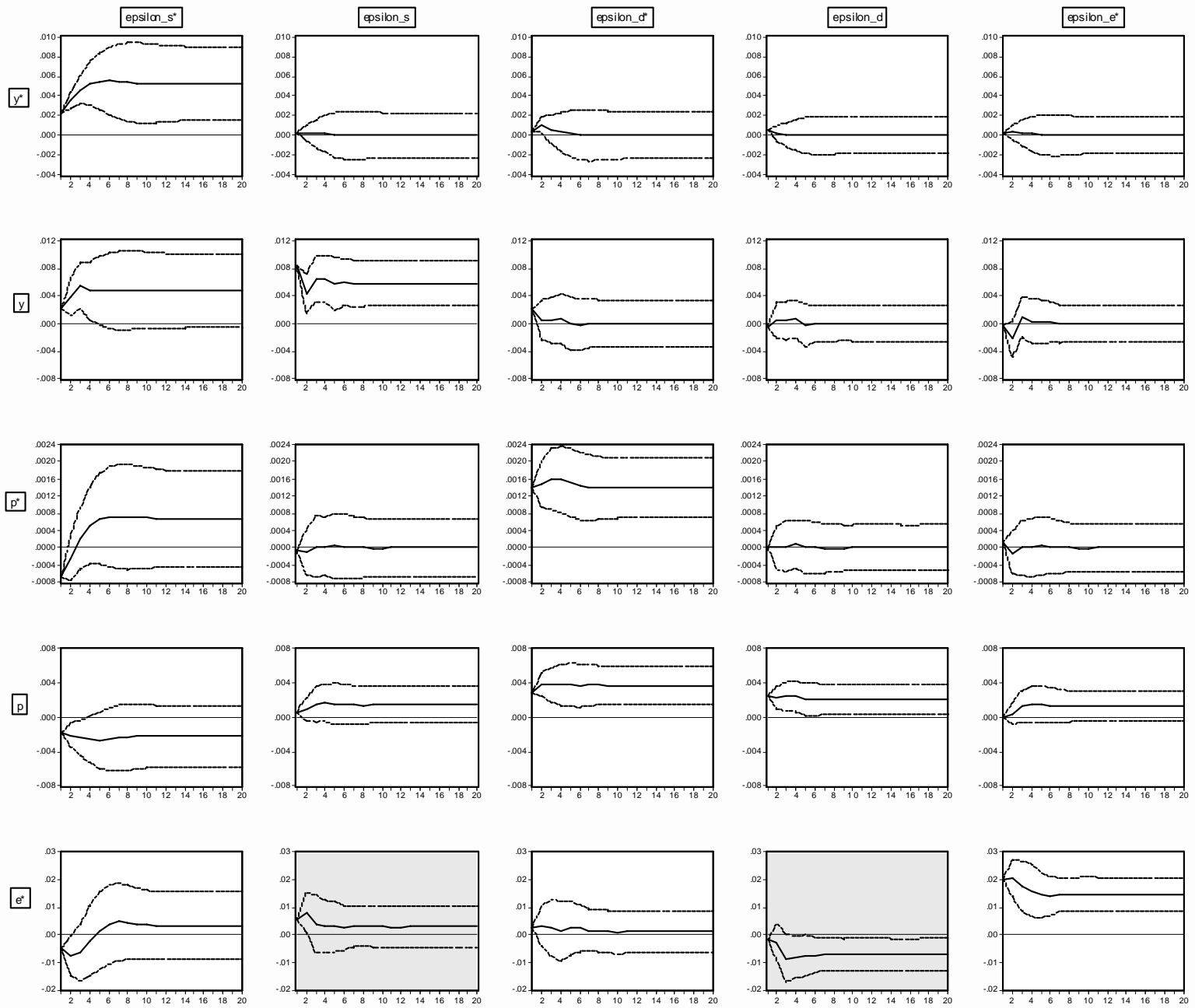


\section{CANADA: Accumulated Response to One Standard Deviation Structural Innovations}
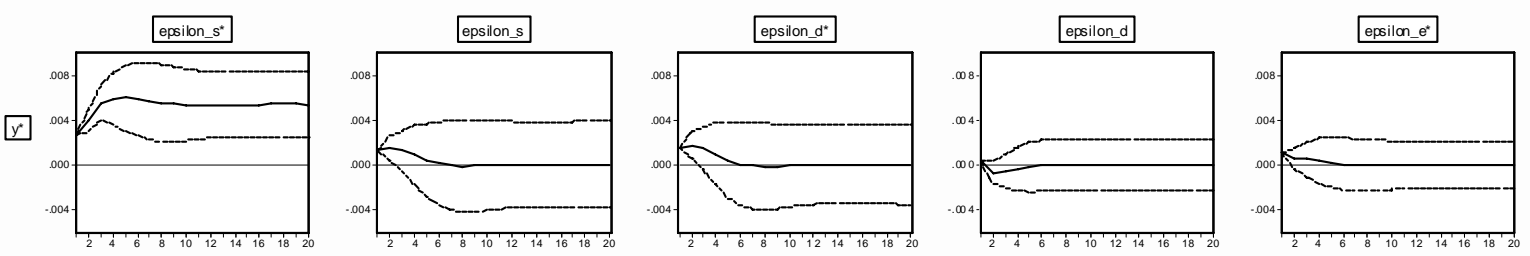

ఐ
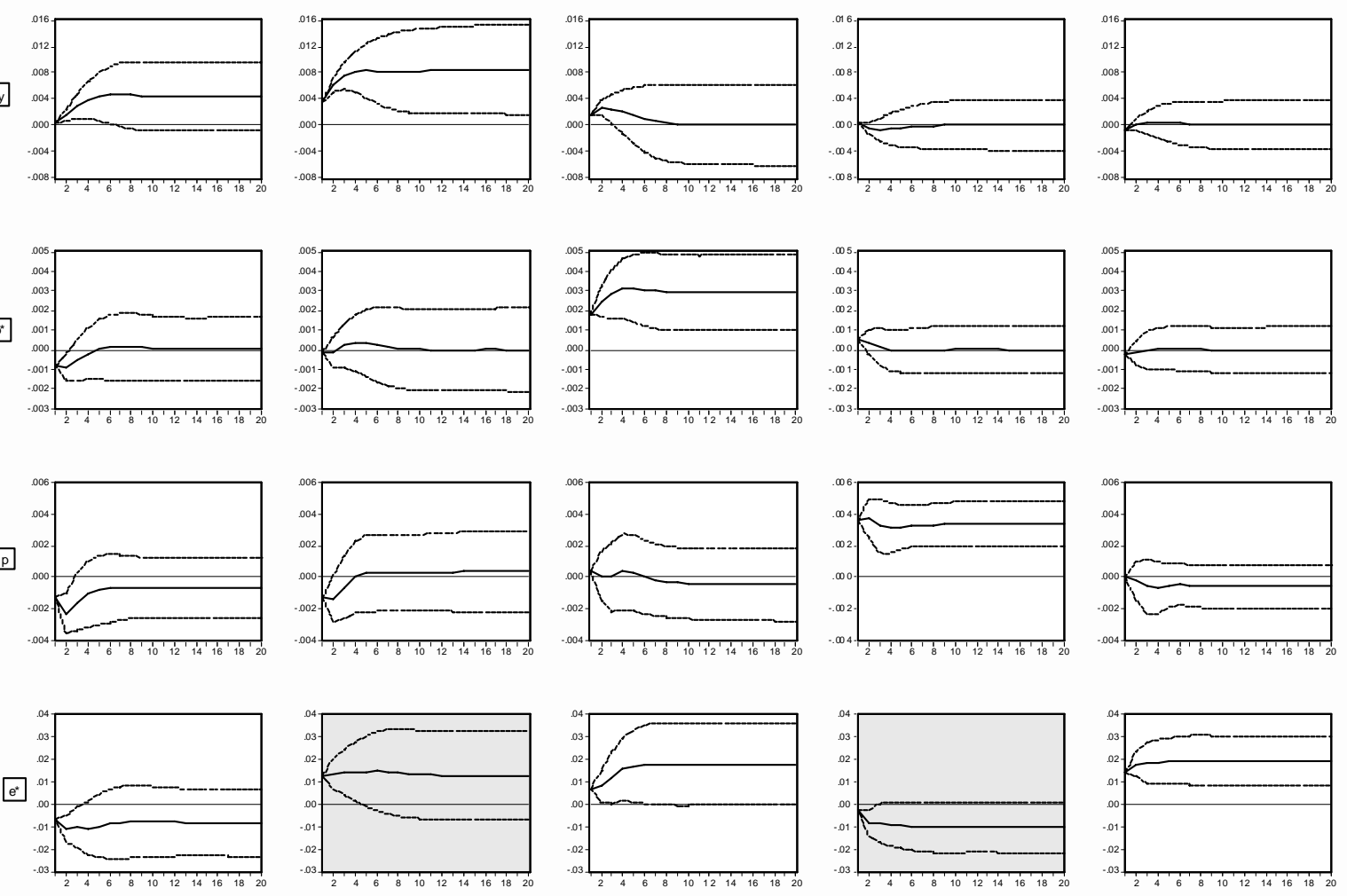


\section{AUSTRALIA: Accumulated Response to One Standard Deviation Structural Innovations}
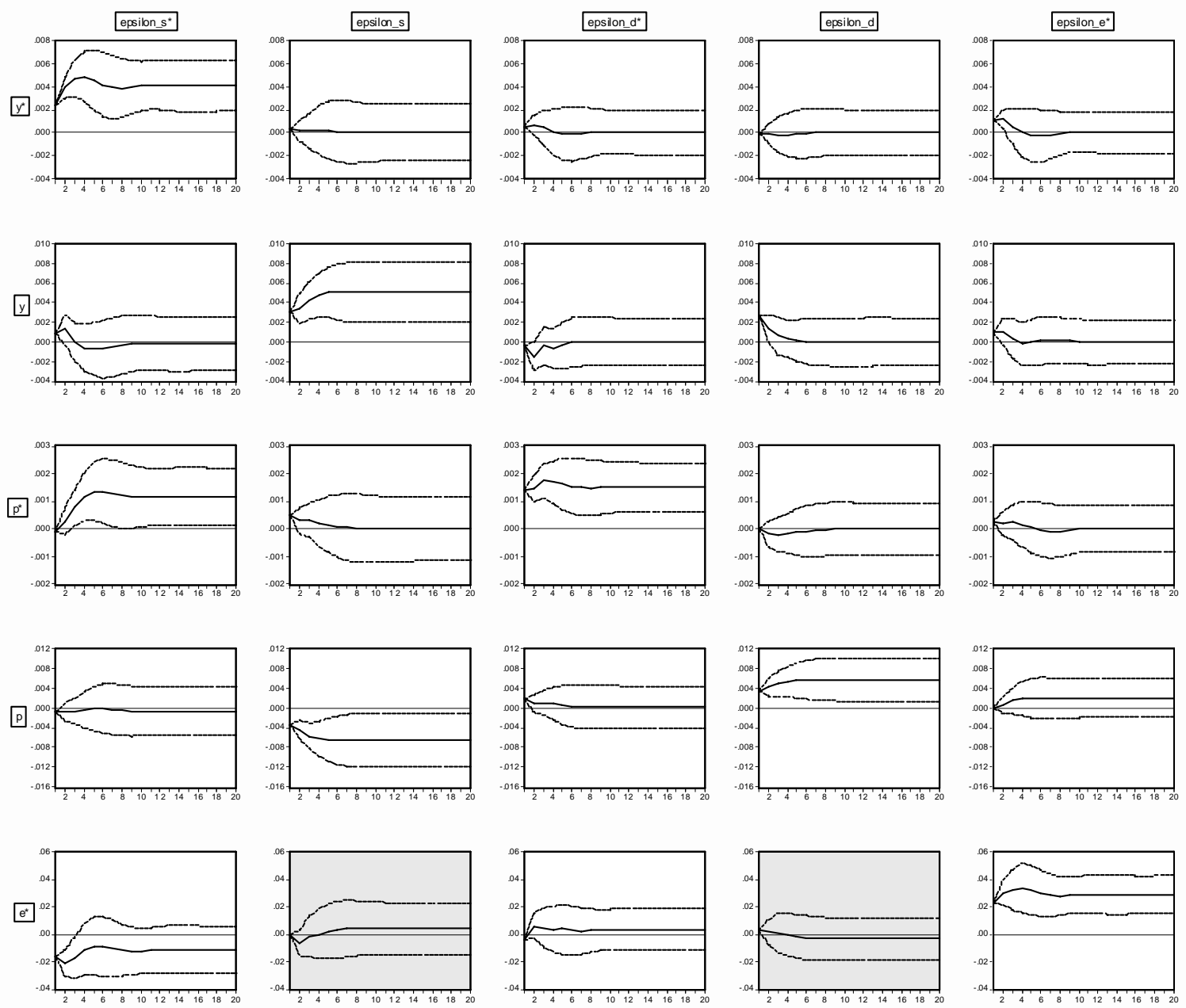
NEW ZEALAND: Accumulated Response to One Standard Deviation Structural Innovations
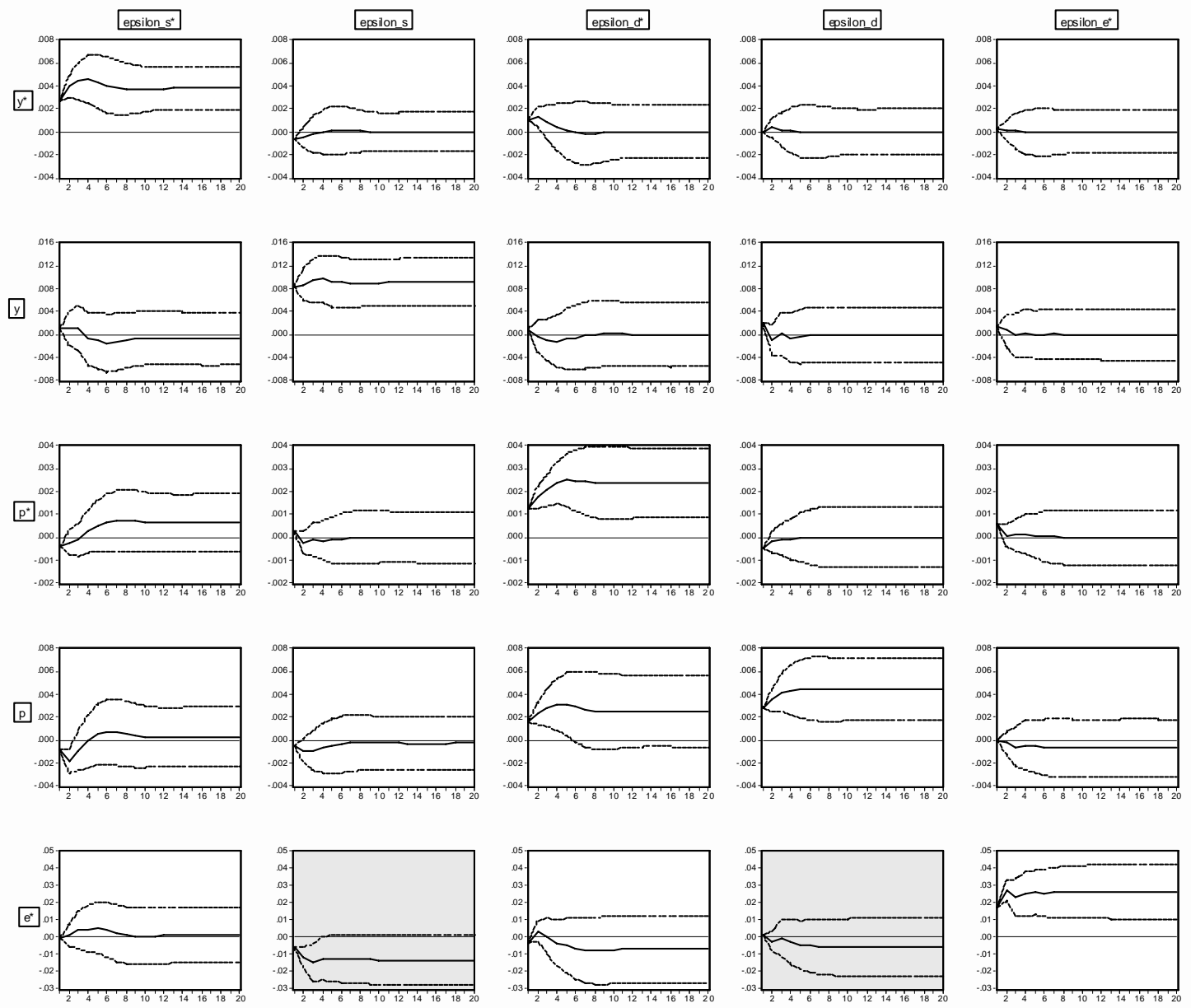
UNITED KINGDOM: Accumulated Response to One Standard Deviation Structural Innovations
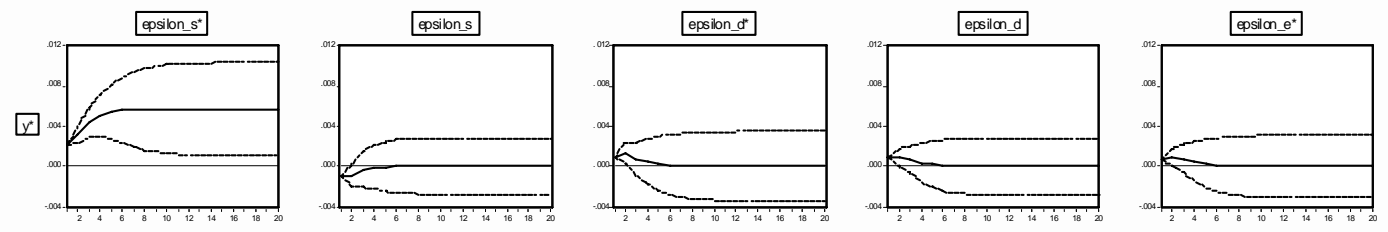

v
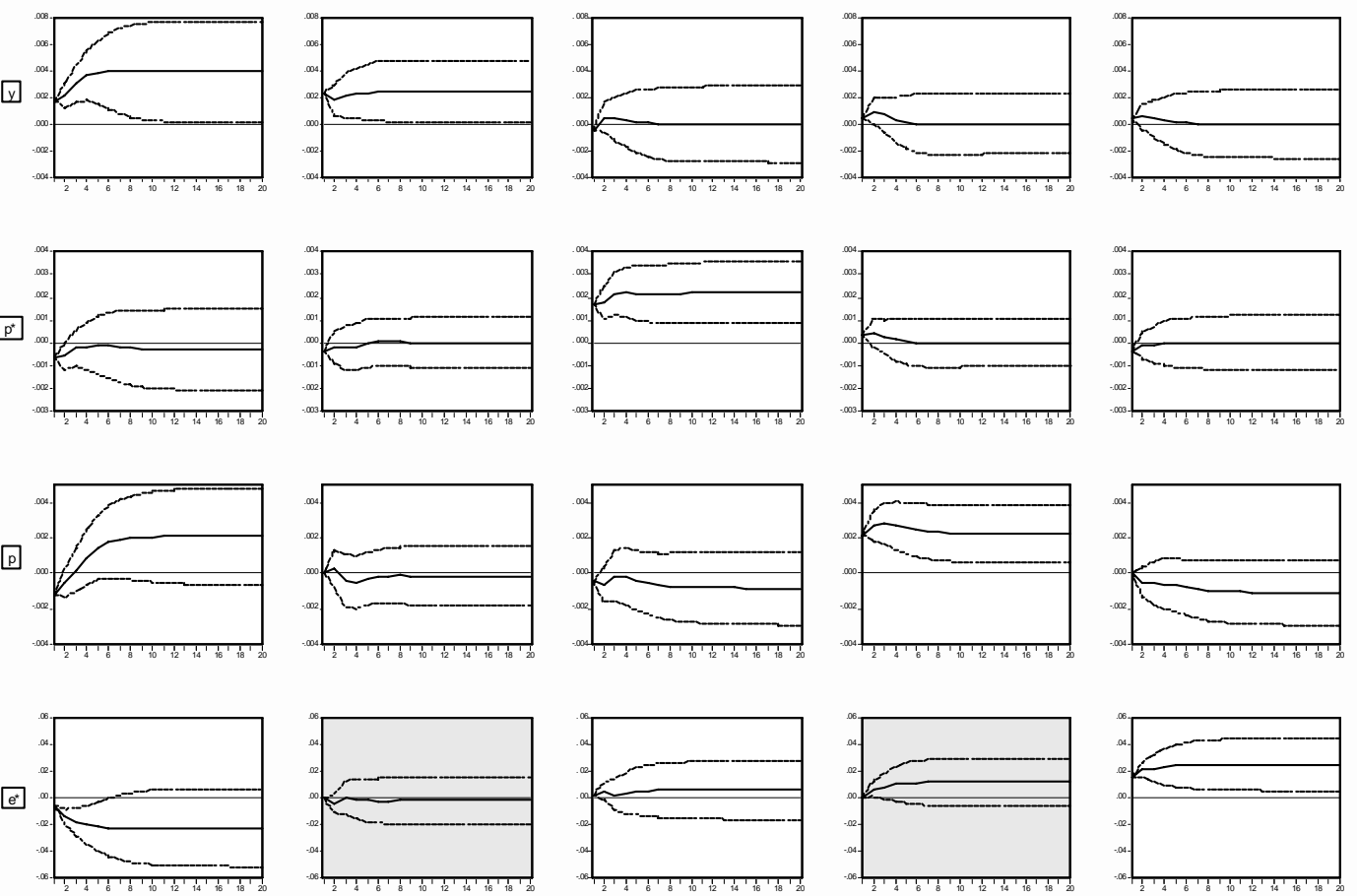


\section{References}

Artis, M. and Ehrmann, M.: 2000, The exchange rate - a shock absorber of source of shocks? a study of four open economies, SPER Discussion Paper 2550 .

Bergvall, A.: 2000, Exchange rate regimes and macroeconomic stability: The case of sweden 1972-1996, Working Paper 2000:25, Department of Economics, Uppsala University.

Bjorneland, H.: 2004, The role of the exchange rate as shock absorber in a small open economy, Open Economies Review 15, 23-43.

Blanchard, O. and Quah, D.: 1989, The dynamic effects of aggregate demand and supply disturbances, American Economic Review 79, 655-673.

Buiter, W. H.: 2000, Optimal currency areas: Why does the exchange rate regime matter? (with an application to UK membership in EMU).

Canzoneri, M., Valles, J. and Vinals, J.: 1996, Do exchange rates move to adress international macroeconomic imbalances?, CEPR Discussion Paper 1498 .

Clarida, R. and Galí, J.: 1994, Sources of real exchange rage fluctuations: How important are nominal shocks?, Centre for Economic Policy Research, Discussion Paper: 951.

Farrant, K. and Peersman, G.: 2004, In the exchange rate a shock absorber of source of shocks? new empirical evidence, Mimeo .

Funke, M.: 2000, Macroeconomic shocks in euroland vs the UK: Supply, demand, or nominal?

Hamilton, J. D.: 1994, Time Series Analysis, Princeton University Press, Princeton.

Hochreiter, E., Korinek, A. and Siklos, P.: 2003, The potential consequences of alternative exchange rate regimes: A study of three candidate regions, International Journal of Finance \& Economics 8, 327-349.

Meese, R. A. and Rogoff, K.: 1983a, Empirical exchange rate models of the seventies: Do they fit out of sample?, Journal of International Economics 14, 3-24. 
Meese, R. A. and Rogoff, K.: 1983b, The out-of-sample failure of empirical exchange rate models: Sampling error or misspecification, in J. A. Frenkel (ed.), Exchange Rates and International Macroeconomics, University of Chicago Press, Chicago.

Obstfeld, M. and Rogoff, K.: 2000, The six major puzzles in international macroeconomics: Is there a common cause?, NBER Macroeconomics Annual 15, 339-390.

Sims, C. A.: 1980, Macroeconomics and reality, Econometrica 48(48), 1-48.

Taylor, M. P.: 2004, Estimating structural macroeconomic shocks through long-run recursive restrictions on vector autoregressive models: The problem of identification, International Journal of Finance and Economics 9, 229-244.

Thomas, A.: 1997, Is the exchange rate a shock absorber? the case of sweden, Working Paper 97/176, IMF, Washington. 
WORKING PAPERS*

Editor: Nils Gottfries

2004:2 Matz Dahlberg, Eva Mörk and Hanna Ågren, Do Politicians’ Preferences Correspond to those of the Voters? An Investigation of Political Representation. 34 pp.

2004:3 Lars Lindvall, Does Public Spending on Youths Affect Crime Rates? 40 pp.

2004:4 Thomas Aronsson and Sören Blomquist, Redistribution and Provision of Public Goods in an Economic Federation. 23 pp.

2004:5 Matias Eklöf and Daniel Hallberg, Private Alternatives and Early Retirement Programs. 30 pp.

2004:6 Bertil Holmlund, Sickness Absence and Search Unemployment. 38 pp.

2004:7 Magnus Lundin, Nils Gottfries and Tomas Lindström, Price and Investment Dynamics: An Empirical Analysis of Plant Level Data. 41 pp.

2004:8 Maria Vredin Johansson, Allocation and Ex Ante Cost Efficiency of a Swedish Subsidy for Environmental Sustainability: The Local Investment Program. 26 pp.

2004:9 Sören Blomquist and Vidar Christiansen, Taxation and Heterogeneous Preferences. $29 \mathrm{pp}$.

2004:10 Magnus Gustavsson, Changes in Educational Wage Premiums in Sweden: 1992-2001. 36 pp.

2004:11 Magnus Gustavsson, Trends in the Transitory Variance of Earnings: Evidence from Sweden 1960-1990 and a Comparison with the United States. 63 pp.

2004:12 Annika Alexius, Far Out on the Yield Curve. 41 pp.

2004:13 Pär Österholm, Estimating the Relationship between Age Structure and GDP in the OECD Using Panel Cointegration Methods. 32 pp.

2004:14 Per-Anders Edin and Magnus Gustavsson, Time Out of Work and Skill Depreciation. $29 \mathrm{pp}$.

2004:15 Sören Blomquist and Luca Micheletto, Redistribution, In-Kind Transfers and Matching Grants when the Federal Government Lacks Information on Local Costs. 34 pp.

2004:16 Iida Häkkinen, Do University Entrance Exams Predict Academic Achievement? 38 pp.

\footnotetext{
* A list of papers in this series from earlier years will be sent on request by the department.
} 
2004:17 Mikael Carlsson, Investment and Uncertainty: A Theory-Based Empirical Approach. 27 pp.

2004:18 N. Anders Klevmarken, Towards an Applicable True Cost-of-Living Index that Incorporates Housing. 8 pp.

2004:19 Matz Dahlberg and Karin Edmark, Is there a "Race-to-the-Bottom" in the Setting of Welfare Benefit Levels? Evidence from a Policy Intervention. $34 \mathrm{pp}$.

2004:20 Pär Holmberg, Unique Supply Function Equilibrium with Capacity Constraints. $31 \mathrm{pp}$.

2005:1 Mikael Bengtsson, Niclas Berggren and Henrik Jordahl, Trust and Growth in the 1990s - A Robustness Analysis. 30 pp.

2005:2 Niclas Berggren and Henrik Jordahl, Free to Trust? Economic Freedom and Social Capital. 31 pp.

2005:3 Matz Dahlberg and Eva Mörk, Public Employment and the Double Role of Bureaucrats. 26 pp.

2005:4 Matz Dahlberg and Douglas Lundin, Antidepressants and the Suicide Rate: Is There Really a Connection? 31 pp.

2005:5 Maria Vredin Johansson, Tobias Heldt and Per Johansson, Latent Variables in a Travel Mode Choice Model: Attitudinal and Behavioural Indicator Variables. $31 \mathrm{pp}$.

2005:6 Katarina Nordblom and Henry Ohlsson, Tax Avoidance and Intra-Family Transfers. 25 pp.

2005:7 Sören Blomquist and Luca Micheletto, Optimal Redistributive Taxation when Government’s and Agents’ Preferences Differ. 22 pp.

2005:8 Ruth-Aïda Nahum, Income Inequality and Growth: A Panel Study of Swedish Counties 1960-2000. 39 pp.

2005:9 Olof Åslund and Peter Fredriksson, Ethnic Enclaves and Welfare Cultures Quasi-experimental Evidence. 37 pp.

2005:10 Annika Alexius and Erik Post, Exchange Rates and Asymmetric Shocks in Small Open Economies. 31 pp.

See also working papers published by the Office of Labour Market Policy Evaluation http://www.ifau.se/ 